\title{
Xanthine Oxidase-derived Hydrogen Peroxide Contributes to Ischemia Reperfusion-induced Edema in Gerbil Brains
}

\author{
Anita Patt, Alden H. Harken, Lisa K. Burton, Timothy C. Rodell, Dale Piermattei, Wagner J. Schorr, Natalie B. Parker, \\ Elaine M. Berger, Irene R. Horesh, Lance S. Terada, Stuart L. Linas, John C. Cheronis, and John E. Repine \\ Departments of Surgery and Medicine, The Webb-Waring Lung Institute and Denver General Hospital \\ at The University of Colorado Health Sciences Center, Denver, Colorado 80262
}

\begin{abstract}
The contribution of toxic $\mathrm{O}_{2}$ metabolites to cerebral ischemia reperfusion injury has not been determined. We found that gerbils subjected to temporary unilateral carotid artery occlusion (ischemia) consistently developed neurologic deficits during ischemia with severities that correlated with increasing degrees of brain edema and brain $\mathrm{H}_{2} \mathrm{O}_{2}$ levels after reperfusion. In contrast, gerbils treated just before reperfusion (after ischemia) with dimethylthiourea (DMTU), but not urea, had decreased brain edema and brain $\mathrm{H}_{2} \mathrm{O}_{2}$ levels. In addition, gerbils fed a tungsten-rich diet for 4,5 , or 6 wk developed progressive decreases in brain xanthine oxidase (XO) and brain XO + xanthine dehydrogenase (XD) activities, brain edema, and brain $\mathrm{H}_{2} \mathrm{O}_{2}$ levels after temporary unilateral carotid artery occlusion and reperfusion. In contrast to tungsten-treated gerbils, allopurinol-treated gerbils did not have statistically significant decreases in brain XO or XO + XD levels, and reduced brain edema and brain $\mathrm{H}_{2} \mathrm{O}_{2}$ levels occurred only in gerbils developing mild but not severe neurologic deficits during ischemia. Finally, gerbils treated with DMTU or tungsten all survived, while $>60 \%$ of gerbils treated with urea, allopurinol, or saline died by $48 \mathrm{~h}$ after temporary unilateral carotid artery occlusion and reperfusion. Our findings indicate that $\mathrm{H}_{2} \mathrm{O}_{2}$ from XO contributes to reperfusion-induced edema in brains subjected to temporary ischemia.
\end{abstract}

\section{Introduction}

It has been proposed that toxic $\mathrm{O}_{2}$ metabolites from xanthine oxidase $(\mathrm{XO})^{1}$ contribute to the development of injury seen during reperfusion of a variety of ischemic tissues $(1,2)$. This impression is based primarily on observations that $\mathrm{XO}$ appears located within endothelial cells (3-6), that $\mathrm{XO}$ generates $\mathrm{O}_{2}$ metabolites in vitro (7), that endothelial cells make $\mathrm{O}_{2}$ metabolites in vitro $(8-10)$, and that treatment with SOD or allopurinol, an XO inhibitor, reduces reperfusion injury in some

Portions of this work were presented at the national meetings of the Western and American Society of Clinical Investigation and the Association for Academic Surgeons.

Address correspondence and reprint requests to Dr. Patt, Box C322, 4200 East Ninth Ave., Denver, CO 80262.

Received for publication 20 August 1987 and in revised form 20 November 1987.

1. Abbreviations used in this paper: DMTU, dimethylthiourea; XD, xanthine dehydrogenase; $\mathrm{XO}$, xanthine oxidase.

J. Clin. Invest.

(c) The American Society for Clinical Investigation, Inc. $0021-9738 / 88 / 05 / 1556 / 07 \$ 2.00$

Volume 81, May 1988, 1556-1562 models of intestinal and cardiac ischemia (11-14). However, there are several problems with making this assumption and using these approaches to determine if XO-derived $\mathrm{O}_{2}$ metabolites contribute to ischemia reperfusion injury in the brain. First, XO activity after ischemia varies from organ to organ. For example, conversion of xanthine dehydrogenase (XD) to $\mathrm{XO}$ during ischemia in rats is faster in liver than in kidney, faster in kidney than in heart, and faster in heart than in lung $(15,16)$. Second, allopurinol and large, highly charged antioxidants, such as SOD and catalase, may not effectively penetrate the blood brain barrier and optimally inhibit processes involving intracellularly generated short-lived $\mathrm{O}_{2}$ metabolites $(17,18)$. Finally, the contribution of $\mathrm{O}_{2}$ metabolites to reperfusion injury needs to be more convincingly established using corroborative measurements of $\mathrm{O}_{2}$ metabolites in biological systems (19).

In the present study, we tested the hypothesis that XO-derived $\mathrm{H}_{2} \mathrm{O}_{2}$ contributes to cerebral reperfusion injury. Brain $\mathrm{H}_{2} \mathrm{O}_{2}$ was measured using aminotriazole inactivation of brain catalase activities (20-22). Brain XO activity was measured using high pressure liquid chromatography (HPLC) (6). We found that administering a single dose of dimethylthiourea (DMTU), a permeant $\mathrm{H}_{2} \mathrm{O}_{2}$ scavenger in vitro (23-25), just before reperfusion, decreased brain edema and brain $\mathrm{H}_{2} \mathrm{O}_{2}$ levels and improved survival in symptomatic gerbils undergoing temporary unilateral carotid occlusion and reperfusion. In parallel, inhibiting brain XO activity using sodium tungstate, which inactivates $\mathrm{XO}$ by preventing the biosynthesis of functionally intact $\mathrm{XO}$ in a process that involves molybdenum (26, 27), also decreased brain edema and brain $\mathrm{H}_{2} \mathrm{O}_{2}$ levels and improved survival in symptomatic gerbils undergoing temporary unilateral carotid artery occlusion and reperfusion. The results indicate that $\mathrm{H}_{2} \mathrm{O}_{2}$ from XO participates in edematous injury during reperfusion of cerebral tissues that have been previously subjected to ischemia.

\section{Methods}

Internal carotid artery ligation and reperfusion. Healthy adult male and female gerbils (50-90 g, Tumblebrook Farms, West Brookfield, MA) were housed at constant temperature under simulated day and night conditions. Gerbils were anesthetized with ketamine $(80 \mathrm{mg} / \mathrm{kg}$, Parke, Davis \& Co., Morris Plains, NJ) and one drop of Dopram (20 $\mathrm{mg} / \mathrm{ml}$, Robins Co., Richmond, VA) sublingually. Using an operating microscope, the left common carotid artery was isolated through a ventral midline incision and clamped with a $5 \times 1-\mathrm{mm}$ KleinhurtKutz microvessel clip (0.38-in straight blade, Edward Weck, Inc., Research Triangle Park, NC). Interruption of blood flow was verified visually and the incision was closed with 3-0 silk suture. Gerbils were observed for $3 \mathrm{~h}$ and then grouped according to neurologic deficit severity (28): 
Group 1, no deficits (asymptomatic); group 2, mild deficits (circling, ptosis, hemiparesis); and group 3, severe deficits (hemiplegia, rolling fits, stupor).

Gerbils with severe neurologic deficits often died if occlusion was allowed to continue beyond $3 \mathrm{~h}$, and therefore were reanesthetized with metaphane (118 ml, Pitman-Moore, Inc., Washington Crossing, $\mathrm{NJ}$ ) and vascular clips were removed after $3 \mathrm{~h}$. Gerbils that died spontaneously during carotid artery occlusion $(<5 \%)$ were eliminated from study. By comparison, gerbils exhibiting no or mild neurologic deficits were reanesthetized and the clip was removed after $6 \mathrm{~h}$. When the clip was removed, resumption of blood flow was verified visually. In separate randomized experiments, gerbils were treated $30 \mathrm{~min}$ before reperfusion with normal saline (0.9\% i.p.), DMTU $(750 \mathrm{mg} / \mathrm{kg}$, Alfa Products, Danvers, MA), or urea $(750 \mathrm{mg} / \mathrm{kg}$, Fisher Scientific Co., Fairlawn, NJ). Gerbils were also treated intraperitoneally with allopurinol $(50 \mathrm{mg} / \mathrm{kg}$ per $\mathrm{d}$ times three, Sigma Chemical Co., St. Louis, $\mathrm{MO}$ ), which had been dissolved in normal saline using heating and mixing with sodium hydroxide $(1 \mathrm{M}, \mathrm{pH} 10)$ to increase solubility or fed a normal protein diet with $0.7 \mathrm{~g} / \mathrm{kg}$ sodium tungstate (ICN Biochemicals, Cleveland, $\mathrm{OH}$ ) and given $\mathrm{H}_{2} \mathrm{O}$ with 10 parts per million tungsten as sodium tungstate (Sigma Chemical Co.) for 4, 5, or 6 wk before carotid artery occlusion. Gerbils fed tungsten had the same weights, hematocrits, and alertness as gerbils fed control diets.

Measurement of brain edema. After reperfusion, gerbils were killed by cervical dislocation and brains were removed. Right (control) and left (experimental) hemispheres were subsequently weighed and dried in an oven at $60^{\circ} \mathrm{C}$ for $48 \mathrm{~h}$. After heating, dry residues were reweighed. Percentages of dry to wet weights $(P)$ were calculated as follows: (dry weight/wet weight) $\times 100=$ percent dry to wet weight $(P)$. Percentages of brain edema were then calculated by the formula: $(P$ right $-P$ left $) / P$ left $\times 100=$ percent brain edema.

Measurement of brain and liver $X O$ and $X O+X D$ activities. Livers and brains were immediately removed from pentobarbital $(10 \mathrm{mg})$ anesthetized gerbils and placed in preweighed containers with $\mathrm{KPO}_{4}$ (50 mM), $\mathrm{Na}_{2} \mathrm{CO}_{3}$ homogenizing buffer (0.2 M, pH 10), PMSF (0.01 $\mathrm{M})$, dithioerythritol $(0.01 \mathrm{M})$, and EDTA (1 mM) (29). Brain tissues were then homogenized in an ultra-turrex homogenizer (Heat Systems Ultrasonics, Farmingdale, NY) at speed 4 for $60 \mathrm{~s}$. After centrifugation at $30,000 \mathrm{~g}$ for $30 \mathrm{~min}$, supernatants were collected from each tube, placed on ice, and then quickly passed at $10^{\circ} \mathrm{C}$ over Sephadex G25 columns previously equilibrated with homogenizing buffer. $\mathrm{XO}$ and total enzyme (XO+XD) activities were measured using HPLC by assay of uric acid produced from xanthine as a function of time. XO activity was measured by preparing sample mixtures of phosphate buffer $(50 \mathrm{mM})$ and xanthine $(1 \mathrm{mM})$. XO+XD activity was measured by preparing sample mixtures of phosphate buffer $(50 \mathrm{mM})$, xanthine ( $1 \mathrm{mM})$, and NAD (6 mM). Standards were also prepared in parallel which contained uric acid $(1 \mathrm{mM})$, xanthine $(1 \mathrm{mM})$, or purified XO. All samples or standards were incubated for $3 \mathrm{~h}$ at $37^{\circ} \mathrm{C}$ in air. After 3 h, TCA (10\%) was added to each tube to achieve a pH 6 to 6.5. Samples were then vortexed and centrifuged at $4,000 \mathrm{~g}$ for $15 \mathrm{~min}$. Aliquots of supernatants $(10 \mu \mathrm{l})$ were injected into the HPLC column (501 pump, 481 detector, and 740 integrator, and $\mathrm{C} 18$ Resolve column, Waters Assoc., Div. of Millipore Corp., Milford, $\mathrm{MA}, \mathrm{KH}_{2} \mathrm{PO}_{4}$ buffer (20 $\mathrm{mM}), \mathrm{pH} 5.7,1 \mu \mathrm{l} / \mathrm{min}$ flow rate) and the uric acid peaks were detected at $290 \mathrm{nM}$. Standards and samples were run in triplicate. Differences between results of two injections from the same sample did not exceed $5 \%$.

Measurement of brain $\mathrm{H}_{2} \mathrm{O}_{2}$ levels. Gerbils were injected intraperitoneally with aminotriazole $(1,000 \mathrm{mg} / \mathrm{kg})$ just before reperfusion (20-22). After reperfusion, gerbils were killed and their brains were removed, rinsed with cold $\mathrm{NaCl}\left(5^{\circ} \mathrm{C}, 0.15 \mathrm{M}\right)$, and stripped of adherent blood vessels. Brains were then separated into right and left hemispheres, weighed, and homogenized in cold potassium phosphate (50 $\mathrm{mM}$ ) Triton X-100 (1\%) buffer (pH 7.0). Catalase activity (30) of brain homogenate samples $(100 \mathrm{ml})$ was assayed in duplicate tubes containing cold sodium perborate $\left(\mathrm{NaBO}_{2} \mathrm{H}_{2} \mathrm{O}_{2} 3 \mathrm{H}_{2} \mathrm{O}\right)$ and $\mathrm{KH}_{2} \mathrm{PO}_{4}(0.05 \mathrm{M})$. Reactions between sodium perborate and brain catalase were stopped after $5 \mathrm{~min}$ by adding $\mathrm{H}_{2} \mathrm{SO}_{4}(1 \mathrm{M})$. Unreacted sodium perborate was then measured by titration with $\mathrm{KMNO}_{4}(0.01 \mathrm{M})$. A blank was also measured using a homogenate sample that had been treated with TCA $(1 \mathrm{M})$ to inactivate catalase. Measurement of aminotriazole levels in brain tissue was performed by combining samples of brain homogenates with TCA. After centrifugation at $2,500 \mathrm{~g} \times 20$ at $5^{\circ} \mathrm{C}$, supernatants were filtered $(0.2-\mu \mathrm{m}$ aerodisc) and then diluted to a total of $5 \mathrm{~cm}^{3}$ using $5 \%$ TCA (31). Sodium nitrite $(1 \mathrm{ml}, 0.01 \mathrm{~N})$ was added and the solutions were swirled. Subsequently, 4,5-dihydroxyl naphthalene-2,7,disulfonoic acid $(1 \mathrm{ml}, 0.0025 \mathrm{M}$ chromatographic acid, grade 1, Sigma Chemical Co.) was added and the tubes were mixed by swirling. Test tubes were immediately placed in boiling water for $2.5 \mathrm{~min}$ and then in ice water. Aminotriazole content of homogenates was measured colorimetrically at $525 \mathrm{nM}$. For clarity of presentation, brain $\mathrm{H}_{2} \mathrm{O}_{2}$ levels were presented as the negative value for the differences in catalase units per milligram of left (affected)-right (control) hemispheres.

Measurement of survival. Survival was assessed at intervals for up to $48 \mathrm{~h}$ after reperfusion.

Statistical analyses. Brain edema, brain $\mathrm{H}_{2} \mathrm{O}_{2}$, brain XO, and brain $\mathrm{XO}+\mathrm{XD}$ data were compared for saline or treated gerbils by one-way analyses of variance using the Student-Newman-Keuls test for multiple comparisons (32). Brain aminotriazole levels from right or left hemispheres were compared by paired Student's $t$ test (32).

\section{Results}

Neurologic deficits, brain edema, and brain $\mathrm{H}_{2} \mathrm{O}_{2}$ levels. Neurologic deficits were assessed during carotid occlusion (ischemia) while brain edema and brain $\mathrm{H}_{2} \mathrm{O}_{2}$ levels were assessed after reperfusion of previously ischemic brains. During unilateral carotid artery occlusion, gerbils consistently developed either no $(\sim 50 \%)$, mild $(\sim 25 \%)$, or severe $(\sim 25 \%)$ neurologic deficits. Neurologic deficit severity occurring during unilateral carotid artery occlusion (ischemia) correlated with degrees of brain edema (as assessed by differences in percent weight gain of left [affected]-right [control] hemispheres, Fig. 1) and brain $\mathrm{H}_{2} \mathrm{O}_{2}$ levels (as assessed by differences in $\mathrm{H}_{2} \mathrm{O}_{2}$ -

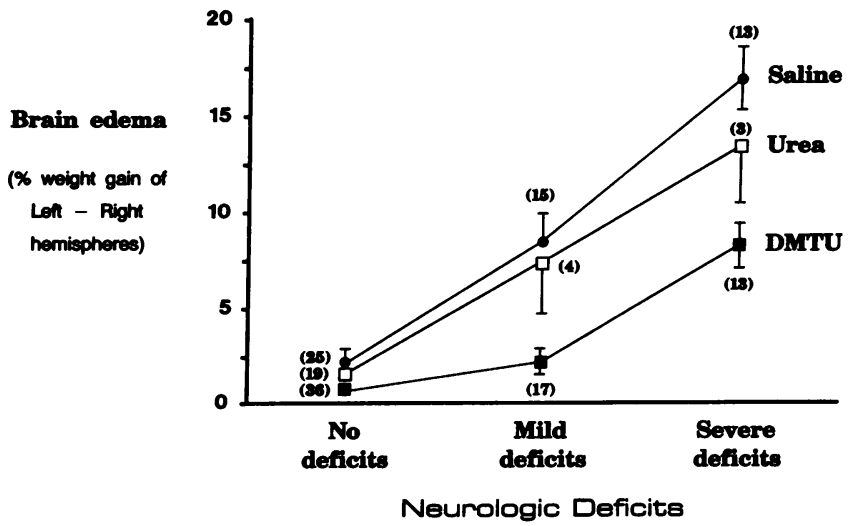

Figure 1. Brain edema (percent weight gain of left-right hemispheres; see Methods) after reperfusion in gerbils developing no, mild, or severe neurologic deficits during temporary unilateral carotid artery occlusion (ischemia). Gerbils that developed mild or severe deficits during ischemia and were then treated with DMTU (but not urea) during reperfusion had less $(P<0.05)$ brain edema after reperfusion than gerbils treated with saline. No differences $(P>0.05)$ were found in brain edema after reperfusion in DMTU-, urea-, or saline-treated gerbils that did not develop neurologic deficits during ischemia. Each value is the mean $\pm 1 \mathrm{SE}$ of the number of determinations shown in parentheses. 
dependent aminotriazole inactivated-catalase activities for left [affected]-right [control] hemispheres, Fig. 2) after reperfusion. Gerbils without neurologic deficits had negligible levels of brain edema and brain $\mathrm{H}_{2} \mathrm{O}_{2}$; gerbils with mild deficits had intermediate levels of brain edema and brain $\mathrm{H}_{2} \mathrm{O}_{2}$; gerbils with severe deficits had the highest levels of brain edema and brain $\mathrm{H}_{2} \mathrm{O}_{2}$.

Effect of DMTU or urea treatment on brain edema and brain $\mathrm{H}_{2} \mathrm{O}_{2}$ levels. Gerbils that developed mild or severe neurologic deficits during temporary unilateral carotid artery occlusion (ischemia), which were then treated with a single dose of DMTU (but not urea) just before reperfusion (after ischemia), had less $(P<0.05)$ brain edema (Fig. 1) and brain $\mathrm{H}_{2} \mathrm{O}_{2}$ levels (Fig. 2) after reperfusion than saline-treated control gerbils. In contrast, brain edema and brain $\mathrm{H}_{2} \mathrm{O}_{2}$ levels were not different in DMTU-, urea-, or saline-treated gerbils that did not develop neurologic deficits after temporary unilateral carotid artery occlusion and reperfusion.

Effect of treatment with tungsten or allopurinol on brain $\mathrm{XO}$ activity, brain edema, and brain $\mathrm{H}_{2} \mathrm{O}_{2}$ levels. Gerbils fed tungsten for 4,5 , or $6 \mathrm{wk}$ had progressively decreased levels of brain (and liver) XO and XO+XD activities (Table I). Complete inhibition (100\%) of brain XO and brain XO+XD activities occurred in gerbils fed tungsten for $6 \mathrm{wk}$. Treatment of gerbils with allopurinol $(50 \mathrm{mg} / \mathrm{kg}$ per $\mathrm{d}$ times three) did not significantly $(P>0.05)$ decrease brain XO and brain XO+XD activities (decreases of only 22 and $23 \%$, respectively). In contrast, allopurinol treatment decreased liver XO and liver XO+XD activities by 49 and $61 \%$, respectively (Table I). After temporary unilateral carotid artery occlusion, gerbils that had developed mild or severe neurologic deficits during ischemia and had been fed tungsten for 4,5 , or 6 wk had progressively decreased brain edema (Fig. 3) and brain $\mathrm{H}_{2} \mathrm{O}_{2}$ levels (Fig. 4) during reperfusion when levels were compared with saline-

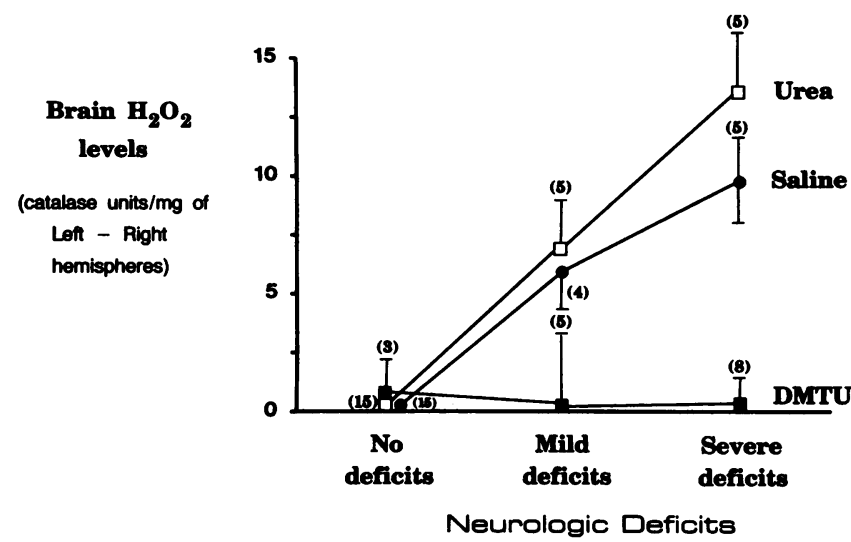

Figure 2. Brain $\mathrm{H}_{2} \mathrm{O}_{2}$ levels (negative value for catalase units per milligram for left-right hemispheres; see Methods) after reperfusion in gerbils developing no, mild, or severe neurologic deficits after temporary unilateral carotid artery occlusion (ischemia). Gerbils that developed mild or severe neurologic deficits during ischemia and were then treated with DMTU (but not urea) during reperfusion had decreased $(P<0.05)$ brain $\mathrm{H}_{2} \mathrm{O}_{2}$ levels after reperfusion compared with gerbils treated with saline. No differences $(P>0.05)$ in brain $\mathrm{H}_{2} \mathrm{O}_{2}$ levels after reperfusion were found in DMTU-, urea-, or salinetreated gerbils that did not develop neurologic deficits during ischemia. Each value is the mean $\pm 1 \mathrm{SE}$ of the number of determinations shown in parentheses. treated gerbils. By comparison, only allopurinol-treated gerbils with mild neurologic deficits had significantly $(P<0.05)$ decreased levels of brain edema (Fig. 5) and brain $\mathrm{H}_{2} \mathrm{O}_{2}$ (Fig. 6). In separate analyses, correlations were found between brain edema and brain $\mathrm{XO}+\mathrm{XD}$ activity (Fig. 7), brain edema and brain $\mathrm{H}_{2} \mathrm{O}_{2}$ levels (Fig. 8), or brain $\mathrm{H}_{2} \mathrm{O}_{2}$ levels and brain $\mathrm{XO}+\mathrm{XD}$ activity (Fig. 9). Aminotriazole levels ( 245 \pm 38 $\mu \mathrm{g} / \mathrm{g}$ brain measured $3 \mathrm{~h}$ after aminotriazole injection) were not different $(P>0.05)$ in right and left hemispheres of saline-, DMTU-, urea-, tungsten-, or allopurinol-treated gerbils (data not shown).

Survival. All DMTU- or tungsten-treated symptomatic gerbils survived for $48 \mathrm{~h}$ while $<40 \%$ of symptomatic gerbils treated with saline, urea, or allopurinol survived for $48 \mathrm{~h}$ after temporary unilateral carotid artery occlusion and reperfusion (Fig. 10).

\section{Discussion}

We found that neurologic deficits occurring during temporary unilateral carotid occlusion (ischemia) correlated and predicted degrees of brain edema and brain $\mathrm{H}_{2} \mathrm{O}_{2}$ levels measured after reperfusion in saline-treated control gerbils. Gerbils without neurologic deficits (during ischemia) had minimal amounts of brain edema and brain $\mathrm{H}_{2} \mathrm{O}_{2}$ levels (after reperfusion); gerbils with mild neurologic deficits (during ischemia) had intermediate levels of brain edema and brain $\mathrm{H}_{2} \mathrm{O}_{2}$ (after reperfusion); and gerbils with severe neurologic deficits (during ischemia) had the greatest brain edema and brain $\mathrm{H}_{2} \mathrm{O}_{2}$ levels (after reperfusion). Gerbils were used for these studies because they commonly lack the posterior communicating artery (incomplete Circle of Willis), and therefore, occlusion of one carotid artery provides a model that is similar to human stroke (33-38). Although the severity of neurologic deficit in each gerbil was not predictable, large groups of gerbils were always tested and the proportions of gerbils that developed either no, mild, or severe neurologic deficits during carotid occlusion (ischemia) were always similar in each test group.

Our study implicates $\mathrm{H}_{2} \mathrm{O}_{2}$ in the development of cerebral edema during reperfusion after ischemia. In saline-treated gerbils subjected to temporary unilateral carotid occlusion (ischemia) and then reperfusion, correlations occurred between brain edema and brain $\mathrm{H}_{2} \mathrm{O}_{2}$ levels (as assessed by differences in catalase levels between left (affected) and right (control) hemispheres of aminotriazole-treated gerbils. Irreversible inactivation of catalase by aminotriazole is a highly specific way of measuring $\mathrm{H}_{2} \mathrm{O}_{2}$ in biological systems (20-22). Differences in catalase inactivation by $\mathrm{H}_{2} \mathrm{O}_{2}$ were not due to alterations in aminotriazole levels that were comparable in left and right hemispheres of brains from treated and control gerbils. Moreover, in gerbils treated with DMTU after ischemia (just before reperfusion), both brain edema and brain $\mathrm{H}_{2} \mathrm{O}_{2}$ levels were decreased after temporary unilateral carotid artery occlusion and reperfusion compared with saline-treated gerbils. DMTU is a highly permeant scavenger that decreases $\mathrm{H}_{2} \mathrm{O}_{2}$ (but not superoxide anion $\left.\left[\mathrm{O}_{\overline{2}}\right]\right)$ in vitro $(23,24)$. It should be emphasized that since DMTU was given only during reperfusion (after ischemia), it did not decrease neurologic deficits occurring during ischemia, but only increases in brain edema and brain $\mathrm{H}_{2} \mathrm{O}_{2}$ levels measured after reperfusion. This finding un- 
Table I. Effect of Tungsten or Allopurinol Treatment on Gerbil Brain and Liver XO or Total Enzyme (XO+XD) Activities

\begin{tabular}{lcccc}
\hline \multicolumn{1}{c}{ Treatment } & Brain XO activity & Brain XO+XD activity & Liver XO activity & Liver XO+XD activity \\
\hline & & & $n g / m g$ \\
Saline & $9 \pm 1(7)^{*}$ & $48 \pm 3.2(10)$ & $35 \pm 3(3)$ & $552 \pm 10(2)$ \\
Tungsten (4 wk) & $5 \pm 5(3)^{\ddagger}$ & $17 \pm 2.0(3)^{\ddagger}$ & $5 \pm 2(2)^{\ddagger}$ & $153 \pm 20(2)^{\ddagger}$ \\
Tungsten $(5 \mathrm{wk})$ & $0(2)^{\ddagger}$ & $8 \pm 2.0(3)^{\ddagger}$ & $0(2)^{\ddagger}$ & $2 \pm(2)^{\ddagger}$ \\
Tungsten (6 wk) & $0(2)^{\ddagger}$ & $0(2)^{\ddagger}$ & $0(2)^{\ddagger}$ & $0(2)^{\ddagger}$ \\
Allopurinol & $7 \pm 5(5)^{\xi}$ & $37 \pm 4.5(5)^{\xi}$ & $18 \pm 1(2)^{\ddagger}$ & $216 \pm 26(3)^{\ddagger}$
\end{tabular}

* Mean \pm SEM (number of determinations in parentheses). ${ }^{\ddagger}$ Value significantly different $(P<0.05)$ from value obtained after treatment with saline. Value not significantly different $(P>0.05)$ from value obtained after treatment with saline.

derscores that neurologic deficit severity during ischemia does not predict increases in brain edema or brain $\mathrm{H}_{2} \mathrm{O}_{2}$ in gerbils treated during reperfusion with DMTU. In contrast, gerbils treated with urea, a potent osmotic agent that does not decrease $\mathrm{H}_{2} \mathrm{O}_{2}$ concentrations in vitro $(23,24)$, had the same increased levels of brain edema or brain $\mathrm{H}_{2} \mathrm{O}_{2}$ as saline-treated gerbils. These studies effectively link $\mathrm{H}_{2} \mathrm{O}_{2}$ or an $\mathrm{H}_{2} \mathrm{O}_{2}$-derived product with the development of brain edema during reperfusion after ischemia (39).

$\mathrm{H}_{2} \mathrm{O}_{2}$ generation appears to be from XO. Tungsten-treated gerbils had progressively decreased brain $\mathrm{XO}$ and brain $\mathrm{XO}+\mathrm{XD}$ activities that corresponded with progressively decreased brain edema and brain $\mathrm{H}_{2} \mathrm{O}_{2}$ levels. Again, note that tungsten treatment did not decrease neurologic deficits occurring during ischemia but only increases in brain edema and brain $\mathrm{H}_{2} \mathrm{O}_{2}$ levels during reperfusion. Both $\mathrm{XO}$ and $\mathrm{XO}+\mathrm{XD}$ activities were measured because in spite of rapid addition of protease and oxidation inhibitors, conversion of XD to XO may be altered during collection, preparation, and/or assay. However, since brains from gerbils treated with tungsten for 6 wk totally lack both $\mathrm{XO}$ and $\mathrm{XD}+\mathrm{XO}$ activity, the potential contribution of $\mathrm{XO}$ is negated regardless of any extrinsic variations in conversion of XD to XO. Similarly, prior findings that tungsten treatment decreases $\mathrm{XO}$ activity in rat lungs and that tungsten-treated cultured lung endothelial cells lack $\mathrm{XO}$ and fail to generate $\mathrm{O}_{\overline{2}}^{\overline{2}}$ support the premise that tungsten decreases XO activity (6). Sulfite oxidase and aldehyde oxidase are two other mammalian enzymes that are known to contain molybdenum, and are therefore potentially susceptible to inhibition by tungsten. In contrast, allopurinol-treated gerbils did not have statistically significant decreases in brain $\mathrm{XO}$ or $\mathrm{XO}+\mathrm{XD}$ activities. In addition, brain edema and brain $\mathrm{H}_{2} \mathrm{O}_{2}$ levels were decreased only in allopurinol-treated gerbils that developed mild but not severe neurologic deficits during ischemia. The reasons for the relative lack of protection with allopurinol are not clear. Although allopurinol effectively reduces reperfusion injury in small intestine and heart (11-13), the relatively large dose of allopurinol that was used may have been poorly transported across the blood brain barrier, where its concentration has been estimated to be only one-third to one-half that of the

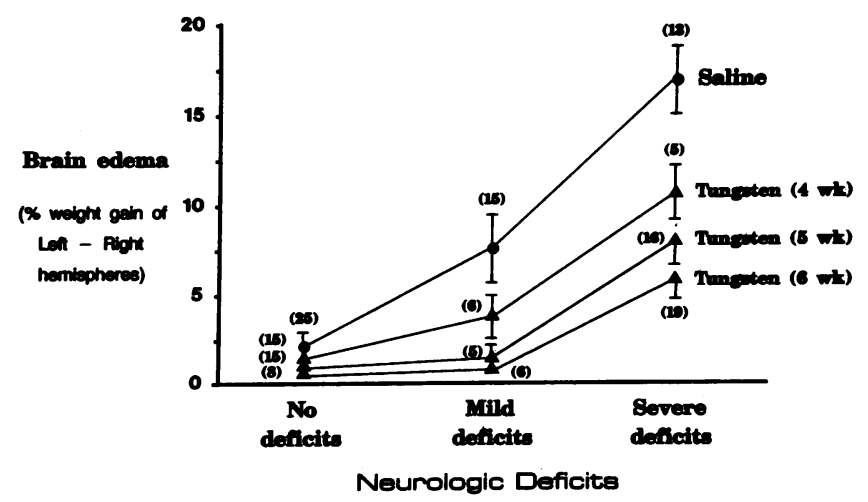

Figure 3. Brain edema (percent weight gain of left-right hemispheres) after reperfusion in gerbils developing no, mild, or severe neurologic deficits during temporary unilateral carotid artery occlusion (ischemia). Gerbils that developed mild or severe neurologic deficits during ischemia and which had been previously fed tungsten-rich diets for 4,5 , or 6 wk had less $(P<0.05)$ brain edema after reperfusion than gerbils fed regular diets. No differences $(P>0.05)$ in brain edema were found after reperfusion in tungsten- or regular diet-fed gerbils that did not develop neurologic deficits during ischemia. Each value is the mean $\pm 1 \mathrm{SE}$ of the number of determinations shown in parentheses.

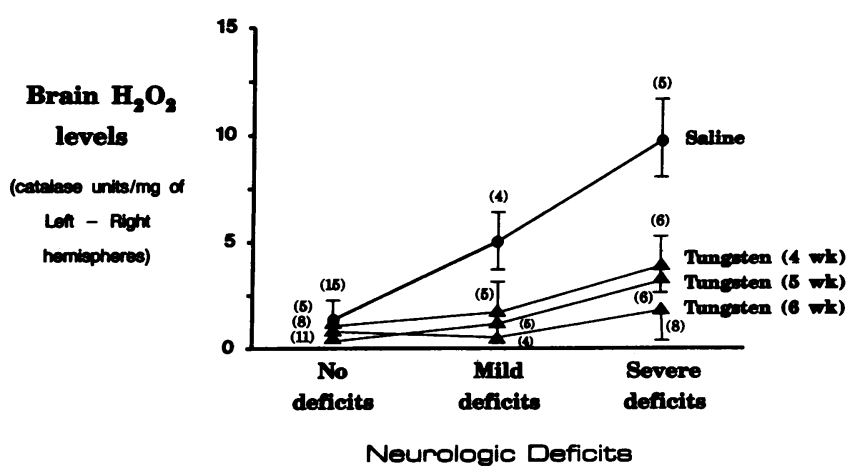

Figure 4. Brain $\mathrm{H}_{2} \mathrm{O}_{2}$ levels (negative value for catalase units per milligram of left-right hemispheres) after reperfusion in gerbils developing no, mild, or severe neurologic deficits after temporary unilateral carotid artery occlusion (ischemia). Gerbils that developed mild or severe neurologic deficits during ischemia and had previously been fed tungsten-rich diets for 4,5 , or 6 wk had decreased $(P<0.05)$ brain $\mathrm{H}_{2} \mathrm{O}_{2}$ levels after reperfusion compared with gerbils fed regular diets. No differences $(P>0.05)$ in brain $\mathrm{H}_{2} \mathrm{O}_{2}$ levels were found after reperfusion in tungsten- or regular diet-fed gerbils that did not develop neurologic deficits during ischemia. Each value is the mean \pm 1 $\mathrm{SE}$ of the number of determinations shown in parentheses. 


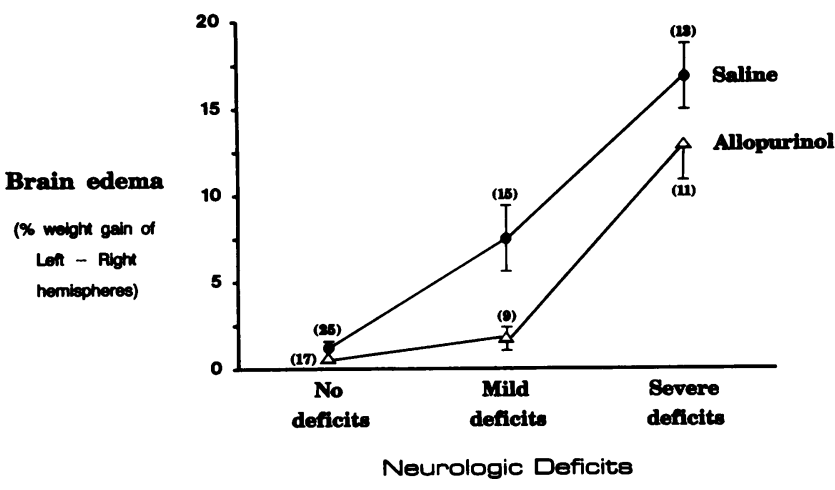

Figure 5. Brain edema (percent weight gain of left-right hemispheres) after reperfusion in gerbils developing no, mild, or severe neurologic deficits after temporary unilateral carotid artery occlusion (ischemia). Gerbils that developed mild neurologic deficits during ischemia and had been previously treated with allopurinol had less $(P<0.05)$ brain edema after reperfusion than gerbils treated with saline. No differences $(P>0.05)$ in brain edema were found after reperfusion in gerbils that developed no or severe neurologic deficits and had been previously treated with allopurinol or saline before temporary unilateral carotid artery occlusion. Each value is the mean $\pm 1 \mathrm{SE}$ of the number of determinations shown in parentheses.

rest of the body $(5,40)$. This possibility was suggested when allopurinol treatment appreciably inhibited liver $\mathrm{XO}$ and liver $\mathrm{XO}+\mathrm{XD}$ activities while decreasing brain $\mathrm{XO}$ and brain $\mathrm{XO}+\mathrm{XD}$ activities only slightly. It is also possible that some $\mathrm{XO}$ inhibition has reversed during preparation and removal of allopurinol by Sephadex filtering. However, this possibility did not occur in livers from gerbils treated with allopurinol or in gerbils treated with tungsten. Allopurinol is a competitive inhibitor that is relatively specific for XO, and by comparison to tungsten does not inhibit sulfite or aldehyde oxidase.

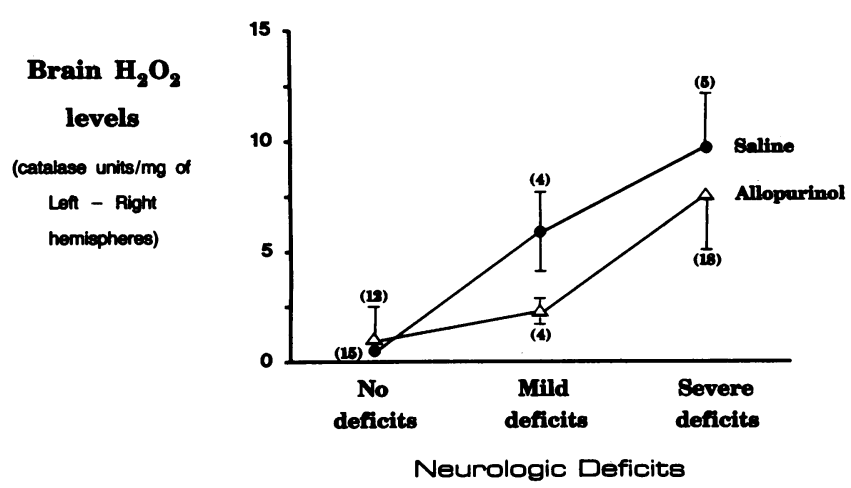

Figure 6. Brain $\mathrm{H}_{2} \mathrm{O}_{2}$ levels (negative value for catalase units per milligram of left-right hemispheres) after reperfusion in gerbils developing no, mild, or severe neurologic deficits after temporary unilateral carotid artery occlusion (ischemia). Gerbils that developed mild neurologic symptoms during ischemia and had been previously treated with allopurinol had decreased $(P<0.05)$ brain $\mathrm{H}_{2} \mathrm{O}_{2}$ levels after reperfusion compared with gerbils treated with saline. No differences $(P>0.05)$ in brain $\mathrm{H}_{2} \mathrm{O}_{2}$ levels after reperfusion were found in gerbils that developed no or severe neurologic deficits during ischemia and had been previously treated with allopurinol or saline before temporary unilateral carotid artery occlusion. Each value is the mean $\pm 1 \mathrm{SE}$ of the number of determinations shown in parentheses.

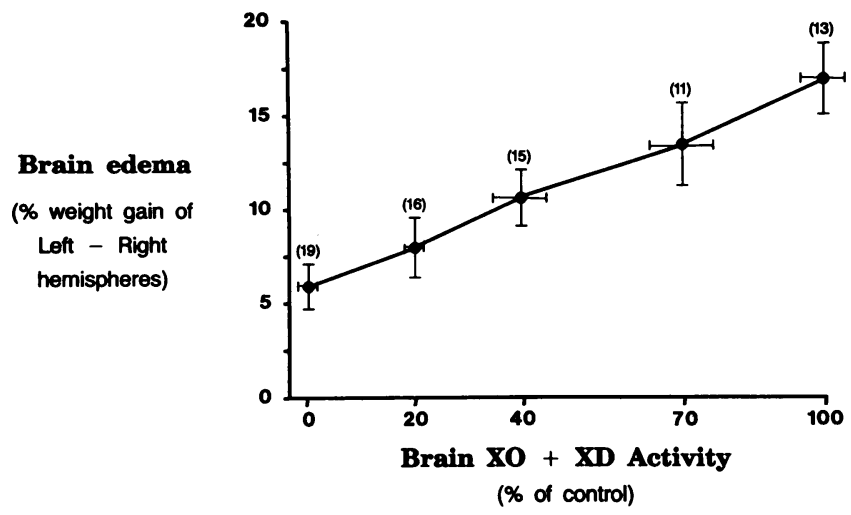

Figure 7. Brain edema (percent weight gain of left-right hemispheres) increased as a function of increases in brain XO+XD activity in gerbils undergoing temporary unilateral carotid artery occlusion (ischemia) and reperfusion. Each value is the mean \pm 1 SE of the number of determinations shown in parentheses.

The specific mechanism by which $\mathrm{H}_{2} \mathrm{O}_{2}$ contributes to acute edematous brain damage is unclear. Molecular $\mathrm{O}_{2}$ is a cofactor in XO-dependent conversion of hypoxanthine to xanthine and xanthine to uric acid. This reaction produces $\mathrm{O}_{\overline{2}}^{\overline{2}}$ by one-electron reduction or $\mathrm{H}_{2} \mathrm{O}_{2}$ by two-electron reduction of $\mathrm{O}_{2}(7,41,42)$. The relative contribution of these two pathways is dependent on both $\mathrm{pH}$ and $\mathrm{O}_{2}$ tension. Higher $\mathrm{O}_{2}$ tensions favor single electron reduction and $\mathrm{O}_{\overline{2}}$ formation (7). Either spontaneously or through the action of $\mathrm{SOD}, \mathrm{O}_{\overline{2}}^{\overline{2}}$ is converted to $\mathrm{H}_{2} \mathrm{O}_{2}$, and then to the more toxic hydroxyl radical ( $(\mathrm{OH})$ by metal catalyzed Fenton or Haber-Weiss reactions (43). $\mathrm{H}_{2} \mathrm{O}_{2}$ or $\mathrm{H}_{2} \mathrm{O}_{2}$-derived products can directly alter key cell proteins, lipids, and nucleic acid molecules in vitro (44). Exogenously generated $\mathrm{H}_{2} \mathrm{O}_{2}$ and related $\mathrm{O}_{2}$ metabolites can also cause reversible abnormalities in contractile mechanisms and leaks in endothelial cells in vitro (45), perfusion pressure increases and increases in thromboxane in isolated lungs (46), and inactivate antiproteases $(39,47)$.

The contribution of intracellular XO-derived $\mathrm{H}_{2} \mathrm{O}_{2}$ to ischemia and reperfusion-induced injury is significant. Gerbils

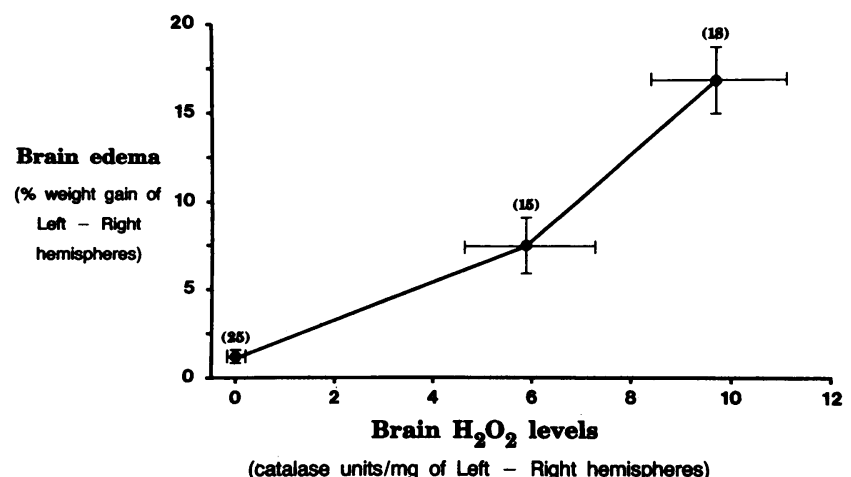

Figure 8. Brain edema (percent weight gain of left-right hemispheres) increased as a function of increases in brain $\mathrm{H}_{2} \mathrm{O}_{2}$ levels (negative value for catalase units per milligram of left-right hemispheres) in gerbils undergoing temporary unilateral carotid artery occlusion (ischemia) and reperfusion. Each value is the mean $\pm 1 \mathrm{SE}$ of the number of determinations shown in parentheses. 


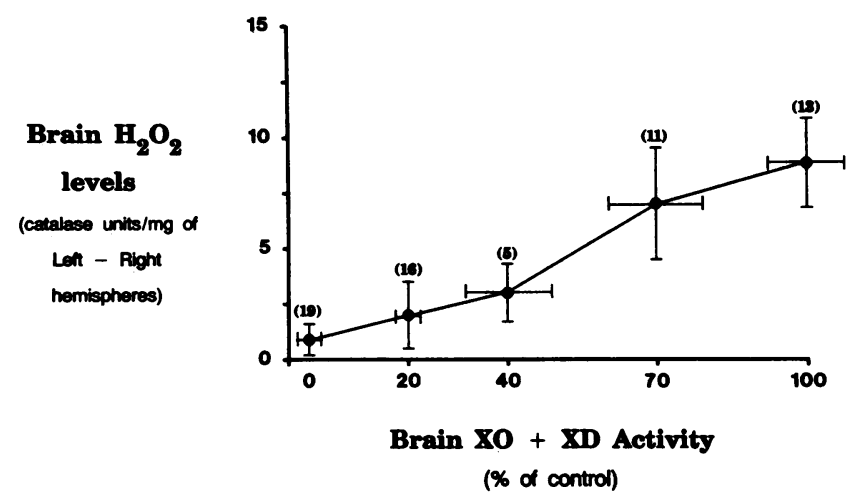

Figure 9. Brain $\mathrm{H}_{2} \mathrm{O}_{2}$ levels (negative value for catalase units per milligram of left-right hemispheres) increased as a function of increases in brain $\mathrm{XO}+\mathrm{XD}$ activity in gerbils undergoing temporary unilateral carotid artery occlusion (ischemia) and reperfusion. Each value is the mean $\pm 1 \mathrm{SE}$ of the number of determinations shown in parentheses.

depleted of $\mathrm{XO}$ by treatment with tungsten or gerbils with reduced brain $\mathrm{H}_{2} \mathrm{O}_{2}$ levels after treatment with DMTU all survived for $48 \mathrm{~h}$ while, in contrast, $>60 \%$ of saline-, urea-, or allopurinol-treated gerbils died after temporary unilateral carotid artery occlusion and reperfusion. It has been shown that intracerebral injection of exogenous XO and hypoxanthine causes cerebral edema and breakdown of the blood brain barrier, and that topical application of XO causes brain endothelial cell permeability that is partially inhibited by SOD and catalase (48-50), but the contribution of intrinsic intracellular $\mathrm{XO}$ has not been defined previously.

While our results suggest that $\mathrm{H}_{2} \mathrm{O}_{2}$ from XO may contribute to acute edematous cerebral edema after ischemia reperfusion injury, a contribution from neutrophils is also possible. Neutrophils accumulate along damaged endothelial cells and appear to contribute to injury in other models of ischemia reperfusion damage (51-55). In addition, $\mathrm{O}_{2}$ metabolites from $\mathrm{XO}$ might also alter endothelial cell surfaces and/or cause release of factors that attract and activate neutrophils $(53,56$, 57). In other situations, stimulated neutrophils or other factors, such as endotoxin, may initiate injury by activating $\mathrm{XO}$ dependent mechanisms that cause a "self-inflicted" damage to endothelial cells $(10,54)$.

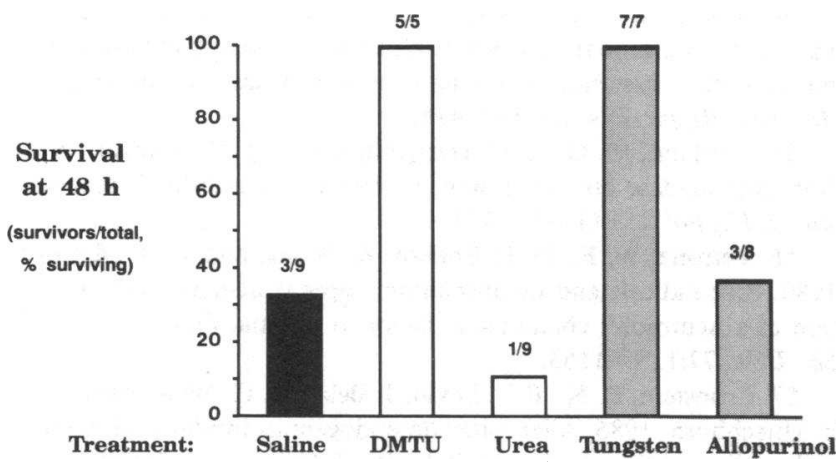

Figure 10. Survival (percent) at $48 \mathrm{~h}$ (number of gerbils surviving/ number tested) after reperfusion of gerbils undergoing temporary unilateral carotid occlusion (ischemia). Gerbils treated with DMTU during reperfusion or fed tungsten for $6 \mathrm{wk}$ had increased $(P<0.05)$ survivals compared with gerbils treated with saline, urea, or allopurinol.

\section{Acknowledgments}

The authors acknowledge the excellent assistance of Jacqueline Borenstein in preparing this manuscript. The authors also appreciate the valuable advice of Drs. Bruce Freeman and Joe Beckman.

This work was supported by grants from the National Institutes of Health (5R01 HL-34486, 5R01 HL-28182, 1R01 HL-35378, and PSOHL-27353), American Heart Association, Council for Tobacco Research, Inc., Swan, Hill, American Express, and Johnson and Johnson Foundations.

Note added in proof. Since submission, another paper has been published which shows that both allopurinol and tungsten treatment decrease reperfusion injury in ischemic isolated rat hearts (58).

\section{References}

1. McCord, J. M. 1985. Oxygen-derived free radicals in postischemic tissue injury. N. Engl. J. Med. 312:159-163.

2. Braunwald, E., and R. A. Lonar. 1985. Myocardial reperfusion. A double-edged sword? J. Clin. Invest. 16:1713-1720.

3. Jarasch, E. D., C. Grund, G. Bruder, H. W. Heid, T. W. Keenan, and W. W. Franke. 1981. Localization of xanthine oxidase in mammary-gland epithelium and capillary endothelium. Cell. 25:67-82.

4. Jarasch, E. D., G. Bruder, and H. W. Heid. 1986. Significance of xanthine oxidase in capillary endothelial cells. Acta Physiol. Scand. Suppl. 548:39-46.

5. Betz, A. L. 1985. Identification of hypoxanthine transport and xanthine oxidase activity in brain capillaries. J. Neurochem. 44:574579.

6. Rodell, T. C., J. C. Cheronis, C. L. Ohnemus, D. J. Piermattei, and J. E. Repine. 1987. Xanthine oxidase mediates elastase-induced injury to isolated lungs and endothelium. J. Appl. Physiol. 63:21592163.

7. McCord, J. M., and I. Fridovich. 1968. The reduction of cytochrome c by milk xanthine oxidase. J. Biol. Chem. 243:5753-5760.

8. Bowman, C. M., K. M. Toth, A. E. Vatter, and J. E. Repine. 1983. Mechanisms of lung injury from hyperoxia. Pulmonary artery endothelial cells but not lung fibroblasts make superoxide anion $\left(\mathrm{O}_{\overline{2}}\right)$. Clin. Res. 31:414. (Abstr.)

9. Rosen, G. M., and B. A. Freeman. 1985. Detection of superoxide generation by endothelial cells. Proc. Natl. Acad. Sci. USA. 1:72697273.

10. Brigham, K. L., B. Meyrick, L. C. Berry, Jr., and J. E. Repine. 1987. Antioxidants prevent endotoxin-mediated injury to endothelial cells. J. Appl. Physiol. 63:840-850.

11. Parks, D. A., G. B. Bulkley, and D. N. Granger. 1983. Role of oxygen-derived free radicals in digestive tract diseases. Surgery (St. Louis). 94:415-421.

12. Hearse, D. J., A. S. Manning, J. M. Downey, and D. M. Yellon. 1986. Xanthine oxidase: a critical mediator of myocardial injury during ischemia and reperfusion. Acta Physiol. Scand. 548:65-78.

13. Parks, D. A., G. B. Bulkley, D. N. Granger, S. R. Hamilton, and J. M. McCord. 1982. Ischemic injury in the cat small intestine: role of superoxide radicals. Gastroenterology. 2:9-15.

14. Parks, D. A., and D. N. Granger. 1986. Xanthine oxidase: biochemistry, distribution and physiology. Acta Physiol. Scand. 548:87-99.

15. Engerson, T. D., T. G. McKelvey, D. B. Rhyne, E. B. Boggio, S. J. Snyder, and H. P. Jones. 1987. Conversion of xanthine dehydrogenase to oxidase in ischemic rat tissues. J. Clin. Invest. 79:1564-1570.

16. Battelli, M. G., E. D. Corte, and F. Stirpe. 1972. Xanthine oxidase type $D$ (dehydrogenase) in the intestine and other organs of the rat. Biochem. J. 126:747-749.

17. Michelson, A. M., and K. Puget. 1980. Cell penetration by exogenous superoxide dismutase. Acta Physiol. Scand. 492:67-80.

18. Joo, F. 1986. The blood brain barrier: new aspects to the function of the cerebral endothelium. Science (Wash. DC). 321:197-198. 
19. Halliwell, B., and M. Grootveld. 1987. The measurement of free radical reactions in humans. Some thoughts for future experimentation. FEBS (Fed. Eur. Biochem. Soc.) Letter 213:9-14.

20. Feinstein, R. N., S. Berliner, and F. O. Green. 1958. Mechanism of inhibition of catalase by 3-amino-1,2,4-triazole. Arch Biochem. Biophys. 76:32-44.

21. Margoliash, E., A. Novogrodsky, and A. Schejter. 1960. Irreversible reaction of 3-amino-1:2:4-triazole and related inhibitors with the protein of catalase. J. Biol. Chem. 74:339-348.

22. Cohen, G., and N. L. Somerson. 1969. Catalase-aminotriazole method for measuring secretion of hydrogen peroxide by microorganisms. J. Bacteriol. 98:543-546.

23. Parker, N. B., E. M. Berger, W. E. Curtis, S. L. Linas, and J. E. Repine. 1985. Hydrogen peroxide causes dimethylthiourea consumption while hydroxyl radical causes dimethylsulfoxide consumption in vitro. J. Free Rad. Biol. Med. 1:415-419.

24. Jackson, J. H., C. W. White, N. B. Parker, J. W. Ryan, and J. E. Repine. 1985. Dimethylthiourea consumption reflects hydrogen peroxide concentrations and the severity of acute edematous lung injury. J. Appl. Physiol. 59:1995-1998.

25. Portz, S. J., K. VanBenthuysen, I. McMurtry, and L. D. Horwitz. 1987. Dimethylthiourea, a diffusable oxygen radical scavenger, reduces myocardial infarct size. Clin. Res. 35:351. (Abstr.)

26. Higgins, E. S., D. A. Richert, and W. W. Westerfield. 1956. Molybdenum deficiency and tungstate inhibition studies. J. Nutr. 59:539-559.

27. Johnson, J. L., K. V. Rajagopalan, and H. J. Cohen. 1974. Molecular basis of the biological function of molybdenum. J. Biol. Chem. 249:859-866.

28. Patt, A., R. B. Rutherford, W. H. Pearce, and J. E. Repine. 1987. Cerebral ischemia-reperfusion in the gerbil. J. Surg. Res. 42:462-466.

29. Stirpe, F., and E. Dellacorte. 1969. The regulation of rat liver xanthine oxidase. J. Biol. Chem. 244:3855-3863.

30. Feinstein, R. N. 1949. Perborate as substrate in a new assay of catalase. J. Biol. Chem. 112:1197-1202.

31. Green, F. O., and R. N. Feinstein. 1957. Quantitative estimation of 3-amino-1,2,4-triazole. Anal. Chem. 29:1658-1660.

32. Worcestor, J. 1966. The statistical method. N. Engl. J. Med. 274:27-36.

33. Levine, S., and D. Sohn. 1969. Cerebral ischemia in infant and adult gerbils: relation to incomplete Circle of Willis. Arch. Pathol. 87:315-335.

34. Harrison, M. J. G., H. Arnold, L. Sedal, and R. W. R. Russell. 1975. Ischemic swelling of cerebral hemisphere in the gerbil. J. Neurol. Neurosurg. Psychiatry. 8:1194-1204.

35. Nakai, K., K. M. A. Welch, and J. S. Meyer. 1977. Critical cerebral blood flow for production of hemiparesis after unilateral carotid occlusion in the gerbil. J. Neurol. Neurosurg. Psychiatry. 40:595-603.

36. Ito, U., K. Ohno, Y. Suganuma, K. Suzuki, and Y. Inaba. 1980. Effect of steroid on ischemic brain edema. Analysis of cytotoxic and vasogenic edema occurring during ischemia and after restoration of blood flow. Stroke. 11:166-182.

37. Avery, S., H. A. Crockard, and R. R. T. Russell. 1984. Evaluation and resolution of edema following severe temporary cerebral ischemia in the gerbil. J. Neurol. Neurosurg. Psychiatry. 47:604-613.

38. Cristie-Pope, B. C., G. C. Palmer, R. B. Chronister, and A. S. Callahan. 1985. Adenylate cyclases and histopathological changes in the gerbil brain following prolonged unilateral ischemia and recirculation. Stroke. 16:710-715.

39. Schraufstatter, I. U., S. D. Revak, and C. G. Cochrane. 1984. Proteases and oxidants in experimental pulmonary inflammatory injury. J. Clin. Invest. 73:1175-1184.

40. Calabresi, P., and A. D. Welch. 1985. Analgesic-antipyretics and antiinflammatory agents: drugs employed in the treatment of gout. In The Pharmacological Basis of Therapeutics. L. S. Goodman,
A. Gilman, editors. New MacMillan Publishing Co., New York. 674-715.

41. McCord, J. M. 1983. The superoxide free radical: its biochemistry and pathophysiology. Surgery (St. Louis). 94:412-414.

42. Olson, T. S., D. P. Ballow, G. Palmer, and V. Massey. 1974. The reaction of xanthine oxidase with molecular oxygen. J. Biol. Chem. 249:4350-4363.

43. Cohen, G. 1977. In defense of Haber Weiss. In Superoxide and Superoxide Dismutases. J. M. McCord and I. Fridovich, editors. Academic Press, Inc., New York. 317-21.

44. Schraufstatter, I. U., D. B. Hinshaw, P. A. Hyslop, R. G. Spragg, and C. G. Cochrane. 1986. Oxidant injury of cells. DNA strand-breaks activate polyadenosine diphosphateribose polymerase and lead to depletion of nicotinamide adenine dinucleotide. J. Clin. Invest. 77:1312-1320.

45. Shasby, D. M., D. E. Lind, S. S. Shasby, J. C. Goldsmith, and G. N. Hunninghake. 1985. Reversible oxidant-induced increases in permeability of cultured endothelium: alterations in cell shape and calcium homeostasis. Blood. 65:605-614.

46. Tate, R. M., H. G. Morris, W. R. Schroeder, and J. E. Repine. 1984. Oxygen metabolites stimulate thromboxane generation and cause vasoconstriction in isolated saline-perfused rabbit lungs. J. Clin. Invest. 74:608-613.

47. Baird, B. R., J. C. Cheronis, R. A. Sandhaus, E. M. Berger, C. W. White, and J. E. Repine. 1986. Oxygen metabolites and neutrophil elastase synergistically cause edematous injury in isolated rat lungs. J. Appl. Physiol. 61:2224-2229.

48. Kontos, H. A., E. P. Wei, J. T. Povlishock, W. L. Dietrich, C. J. Majiera, and E. F. Ellis. 1980. Cerebral arteriolar damage by arachidonic acid and prostaglandin $G_{2}$. Science (Wash. DC). 209:12421245.

49. Wei, E. P., R. G. Lamb, and H. A. Kontos. 1982. Increased phospholipase $\mathrm{C}$ activity after experimental brain injury. J. Neurosurg. 56:695-698.

50. Wei, E. P., C. W. Christman, H. A. Kontos, and J. T. Povlishcok. 1985. Effects of oxygen radicals on cerebral arterioles. Am. J. Physiol. 248:H157-H162.

51. Demopoulos, H. B., E. J. Flamm, D. D. Pietronigro, and M. Seligman. 1980. The free radical pathology and the microcirculation in the major central nervous system disorders. Acta Physiol. Scand. Suppl. 492:91-119.

52. Engler, R. L., M. D. Dahlgren, D. D. Morris, M. A. Peterson, and G. W. Schmid-Schonbern. 1986. Role of leukocytes in response to acute myocardial ischemia and reflow in dogs. Am. J. Physiol. 251:H314-H322.

53. Linas, S. L., E. M. Berger, and J. E. Repine. 1986. Neutrophils contribute to renal ischemia reperfusion injury. Am. Soc. Nephrol. 19:212. (Abstr.)

54. Repine, J. E., T. C. Rodell, J. C. Cheronis, S. L. Linas, and A. Patt. 1987. Pulmonary oxygen toxicity and ischemia-reperfusion: a mechanism in common involving xanthine oxidase and neutrophils. Am. Rev. Respir. Dis. 136:483-485.

55. Grisham, M. G., L. C. Hernandez, and D. N. Granger. 1986 Xanthine oxidase and neutrophil infiltration in intestinal ischemia Am. J. Physiol. 251:G567-G574.

56. Petrone, W. F., D. F. English, K. Wong, and J. M. McCord. 1980. Free radicals and inflammation: superoxide-dependent activation of a neutrophil chemotactic factor in plasma. Proc. Natl. Acad. Sci. USA. 77:1159-1163.

57. Cronstein, B. N., R. I. Levin, J. Belanoff, G. Weissmann, and R. Hirschhorn. 1986. Adenosine: an endogenous inhibitor of neutrophil-mediated injury to endothelial cells. J. Clin. Invest. 78:760-770.

58. Brown, J. M., L. S. Terada, M. A. Grosso, G. J. Whitmann, S. E. Velasco, A. Patt, A. H. Harken, and J. E. Repine. 1988. Xanthine oxidase produces hydrogen peroxide which contributes to reperfusion injury of ischemic, isolated, perfused rat hearts. J. Clin. Invest. 81:1297-1301. 